\title{
THE HEART IN MYOTONIA ATROPHICA
}

\author{
BY \\ . J. D. SPILLANE \\ From the United Cardiff Hospitals, Cardiff \\ Received February 8, 1951
}

The sudden and unexpected death from heart failure of a man suffering from myotonia atrophica prompted this enquiry. No evidence of grave heart disease had been detected, though looked for, but the patient (Case 1) died suddenly from what was probably acute left ventricular failure while in bed in hospital during investigation of his neurological disorder. Post mortem there was no cardiac abnormality apart from ventricular dilatation but the A-V bundle was not examined.

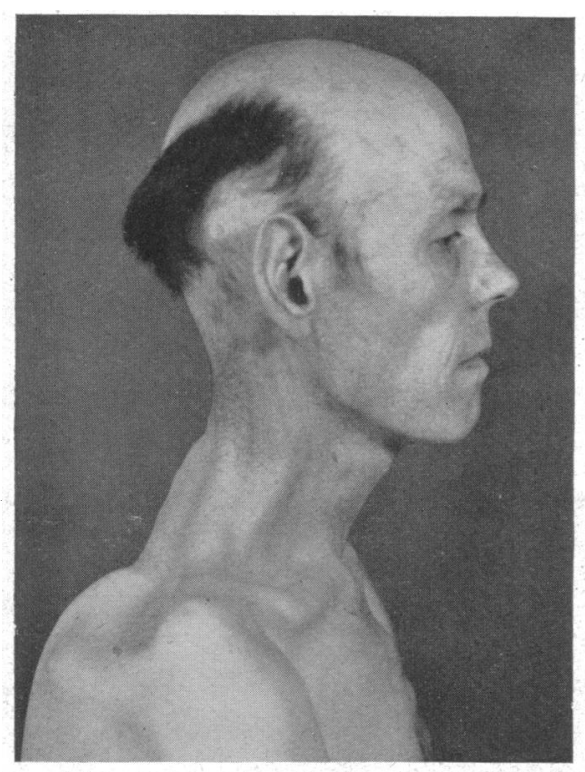

Fig. 1.-Case 1. Duration of symptoms fifteen years; longest in this series. He died suddenly and unexpectedly of acute heart failure. Contrast gross neurological features with slight changes in cardiovascular system (Table II).

It was the experience of Evans (1944) after studying 13 cases that " signs discovered during the examination of the cardiovascular system contribute to the surer and earlier diagnosis of myotonia atrophica." He pointed out that the pulse is often small ( $8^{\circ}$ out of 13$)$, the blood pressure is sometimes low (5 out of 13), and the first heart sound in the mitral area commonly. shows impurity and/or splitting (10 out of 13). Changes that commonly characterize the electrocardiogram include prolongation of the $\mathrm{P}-\mathrm{R}$ period (10 out of 13 greater than $0.20 \mathrm{sec}$.), low voltage of the $P$ wave ( 8 out of 13 ), or notching of the QRS complex (9 out of 13) and left axis deviation (7 out of 13). Evans noted that neither the age of the patient, the duration of symptoms (over five years in 5; no other details given), nor their severity appeared to determine the presence of cardiographic abnormalities.

As Evans pointed out, there is little reference in the English literature to involvement of the heart in myotonia. Adie and Greenfield (1923), who reported the first post-mortem study of the disease in this country, mentioned that a slow heart rate had been observed in isolated cases (Griffith, 1912; Röhrer, 1916; Maas and Zondek, 1920), but in the one case examined with the electrocardiogram the $\mathrm{P}-\mathrm{R}$ interval was normal $(0 \cdot 16$ to $0 \cdot 17)$. Thaysen (1943) found electrocardiographic reports in 30 of the published cases of the disease; in 13

the $\mathbf{P}-\mathbf{R}$ interval was prolonged. The additional available evidence on the subject is summarized in Table I. In the majority of these reports it can be inferred that the disease was well established when the cardiac changes were noted. In some cases insufficient evidence is published.

In the present series of 16 cases the following cardiovascular abnormalities were noted (Table II). The pulse was small in six, and slow (50) in two cases. The blood pressure was raised in one case; the systolic pressure was never below 100 , but was between 100 and 110 in seven cases. There was 
TABLE I

Published References to the Heart in Myotonia Atrophica

\begin{tabular}{|c|c|c|}
\hline Cardiovascular changes & $\begin{array}{c}\text { No. } \\
\text { of cases }\end{array}$ & Reference \\
\hline 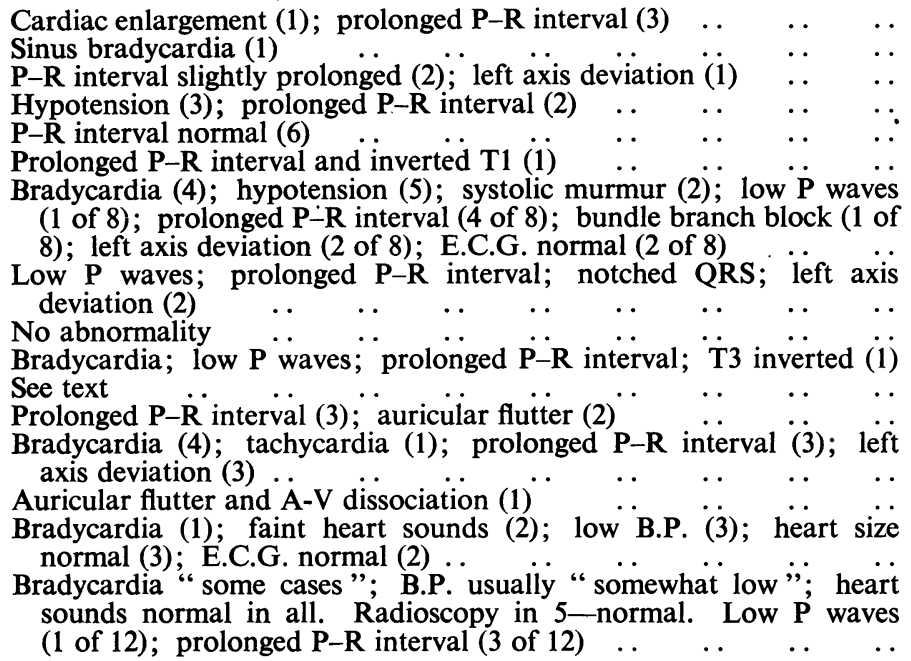 & $\begin{array}{r}13 \\
3 \\
11 \\
1 \\
13 \\
4 \\
8 \\
1 \\
3\end{array}$ & $\begin{array}{l}\text { Maas and Zondek, } 1920 . \\
\text { Havier and Decourt, } 1933 . \\
\text { Guillain and Rouques, } 1932 . \\
\text { d'Antona, } 1935 . \\
\text { Kolb et al., } 1938 . \\
\text { Mondon and Pasquet, } 1939 . \\
\text { Waring } \text { et al., } 1940 . \\
\text { Carrillo, 1941. } \\
\text { Segura and Lanari, } 1941 . \\
\text { Carrot } \text { et al., } 1943 . \\
\text { Evans, 1944. } \\
\text { Biörck and Nylin, } 1944 . \\
\text { Ask-Upmark, } 1944 . \\
\text { Broustet } \text { et al., } 1945 . \\
\text { Black and Ravin, } 1947 . \\
\text { Thomasen, } 1948 .\end{array}$ \\
\hline
\end{tabular}

TABLE II

The Cardiovascular Changes in Sixteen Cases of Myotonia Atrophica

\begin{tabular}{|c|c|c|c|c|c|c|c|c|c|c|c|}
\hline \multirow[b]{2}{*}{$\begin{array}{l}\text { Case } \\
\text { No. }\end{array}$} & \multirow{2}{*}{$\begin{array}{c}\text { Age } \\
\text { in } \\
\text { years }\end{array}$} & \multirow{2}{*}{$\begin{array}{l}\text { Duration } \\
\text { of } \\
\text { symptoms } \\
\text { (years) }\end{array}$} & \multicolumn{2}{|r|}{ Pulse } & \multirow[b]{2}{*}{ B.P. } & \multirow[b]{2}{*}{$\begin{array}{l}\text { 1st heart } \\
\text { sound }\end{array}$} & \multirow[b]{2}{*}{$\begin{array}{l}\text { Size of } \\
\text { heart* }\end{array}$} & \multicolumn{4}{|c|}{ Electrocardiographic changes } \\
\hline & & & Rate & Character & & & & $\begin{array}{l}\text { Voltage } \\
\text { of } \\
\mathrm{P} \text { wave }\end{array}$ & $\begin{array}{c}\mathbf{P}-\mathbf{R} \\
\text { interval }\end{array}$ & QRS & $\begin{array}{l}\text { Other } \\
\text { changes }\end{array}$ \\
\hline $\begin{array}{r}1 \\
2 \\
3 \\
4 \\
5 \\
6 \\
7 \\
8 \\
9 \\
10 \\
11 \\
12 \\
13 \\
14 \\
15 \\
16\end{array}$ & $\begin{array}{l}51 \\
48 \\
39 \\
49 \\
26 \\
37 \\
52 \\
39 \\
41 \\
40 \\
43 \\
24 \\
40 \\
48 \\
48 \\
29\end{array}$ & $\begin{array}{r}15 \\
8 \\
11 \\
10 \\
10 \\
3 \\
2 \\
10 \\
12 \\
9 \\
10 \\
1 \\
\frac{1}{2} \\
? \\
10 \\
3\end{array}$ & $\begin{array}{l}65 \\
65 \\
75 \\
95 \\
65 \\
50 \\
80 \\
65 \\
85 \\
58 \\
60 \\
72 \\
70 \\
80 \\
70 \\
50\end{array}$ & $\begin{array}{c}\text { small } \\
\text { N. } \\
\text { small } \\
\text { small } \\
\text { small } \\
\text { small } \\
\text { N. } \\
\text { N. } \\
\text { N. } \\
\text { N. } \\
\text { small } \\
\text { N. } \\
\text { N. } \\
\text { N. } \\
\text { N. } \\
\text { N. }\end{array}$ & $\begin{array}{l}135 / 75 \\
110 / 70 \\
110 / 80 \\
110 / 70 \\
120 / 70 \\
110 / 80 \\
110 / 70 \\
120 / 85 \\
120 / 70 \\
115 / 80 \\
105 / 75 \\
115 / 80 \\
155 / 90 \\
130 / 80 \\
130 / 95\end{array}$ & $\begin{array}{c}\text { N. } \\
\text { split } \\
\text { N. } \\
\text { N. } \\
\text { split } \\
\text { split } \\
\text { impure } \\
\text { N. } \\
\text { N. } \\
\text { split } \\
\text { split } \\
\text { N. } \\
\text { N. } \\
\text { N. } \\
\text { N. } \\
\text { N. }\end{array}$ & $\begin{array}{l}+ \\
\text { N. } \\
\text { N. } \\
\text { N. } \\
\text { N. } \\
\text { N. } \\
\text { N. } \\
\text { N. } \\
++ \\
\text { N. } \\
\text { N. } \\
\text { N. } \\
\text { N. } \\
\text { N. } \\
\text { N. } \\
\text { N. }\end{array}$ & $\begin{array}{c}\text { low } \\
\text { low } \\
\text { N. } \\
\text { low } \\
\text { low } \\
\text { N. } \\
\text { N. } \\
\text { low } \\
\text { low } \\
\text { N. } \\
\text { low } \\
\text { N. } \\
\text { N. } \\
\text { N. } \\
\text { N. } \\
\text { low }\end{array}$ & $\begin{array}{l}0 \cdot 16 \\
0 \cdot 21 \\
0 \cdot 21 \\
0 \cdot 18 \\
0 \cdot 18 \\
0 \cdot 20 \\
0 \cdot 21 \\
0 \cdot 20 \\
0 \cdot 22 \\
0 \cdot 21 \\
0 \cdot 24 \\
0 \cdot 16 \\
0 \cdot 18 \\
0 \cdot 18 \\
0 \cdot 17 \\
0 \cdot 16\end{array}$ & $\begin{array}{l}\text { N. } \\
\text { sl. } \dagger \\
\text { N. } \\
\text { N. } \\
\text { sl } \dagger \\
\text { N. } \\
\text { N. } \\
\text { N. } \\
\text { N. } \\
\text { N. } \\
\text { N. } \\
\text { N. } \\
\text { N. } \\
\text { N. } \\
\text { N. } \\
\text { N. }\end{array}$ & 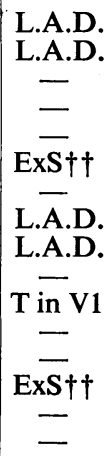 \\
\hline
\end{tabular}

$*+$ indicates slight, and ++ moderate enlargement.

$\dagger$ Sl. indicates slurred.

$+\dagger$ Extrasystoles. 
splitting of the first heart sound in the mitral area in five cases; in one this sound was impure. The electrocardiogram showed low voltage of the $\mathbf{P}$ waves in eight; in the first lead the voltage of the $\mathrm{P}$ wave was always low. The $\mathrm{P}-\mathrm{R}$ interval was more than $0.20 \mathrm{sec}$. in six, and less than $0 \cdot 20 \mathrm{sec}$. in eight cases. Slurring of the QRS complex was present twice. In four cases there was left axis deviation.

Radioscopy revealed a normal heart outline in thirteen patients. In Case 7 the heart was small; in Cases 1 and 9 there was slight and moderate enlargement respectively. Case 14 had recently suffered from myxœdema with considerable cardiac enlargement; treatment with thyroid had reduced the heart to normal size and produced corresponding clinical improvement. Iow basal metabolic rates have been reported in myotonia atrophica but Thomasen (1948) stated that myxœedema has not been described as a complication of myotonia atrophica. He commented on the frequency of myotonic phenomena and muscular hypertrophy in myxœdema.

These findings are in general agreement with those described by Evans. Where abnormalities were observed they corresponded in character with those he described. A small pulse, a relatively low blood pressure, and splitting of the first heart sound are frequent findings in this disease. The electrocardiogram frequently reveals low $\mathbf{P}$ waves and a prolonged $\mathbf{P}-\mathbf{R}$ interval. Quinine (10 grains t.i.d.) did not influence these signs although it frequently reduced the myotonia.

Such findings are interesting and indicate that involvement of the heart should be considered in myotonia atrophica. But their value in the early diagnosis of the disease, as claimed by Evans, is open to question. It certainly cannot be deduced from a study of this series. In ten of the sixteen cases symptoms were present for eight years or more. In only six (Cases 6, 7, 12, 13, 14 and 16) could it be said that the disease was in an early stage. In Case 14 (a brother of Case 7) the duration of the disease could not be assessed as he had also been suffering from myxœdema. In the remaining "early" cases symptoms had been present for three years, two years, one year, six months, and three years respectively. In Cases 12 and 13 the heart was normal. In Case 7 the only abnormalities were an impure first heart sound, a small heart and a P-R interval of $0.21 \mathrm{sec}$. In Case 6 there was a slow pulse (50), splitting of the first heart sound, and a P-R interval of $0 \cdot 20 \mathrm{sec}$. In Case 16 the pulse was slow (50) and the P waves low in all leads. Thus, of five " early" cases of this disease the heart was normal in two; in the remaining three the amount of cardiac abnormality was not great. By contrast, the neurological abnormalities in these five cases were considerable. They readily provided a diagnosis.

Case 6. Man, aged 37 years: Symptoms were of three years duration. He had not been able to do his work for one year (light labourer). He complained of increasing muscular weakness. There was atrophy of the neck muscles and of the calf muscles with complete areflexia and characteristic myotonia. The latter was observed in the tongue, the muscles of the hands and forearms and of the eyelids. There was evidence of personality and intellectual deterioration.

Case 7. Man, aged 52 years. Symptoms of two years duration. He gave up his work in a foundry eighteen months previously on account of increasing weakness and pains in his limbs. He took up light work on a farm. He was bald, the testicles were atrophied, and there was marked generalized muscular weakness. His voice was weak and he had difficulty in swallowing. Considerable wasting of the calf and peroneal muscles. Myasthenic facies, absent deep reflexes, myotonia of the hand muscles, and typical atrophy of the neck muscles.

Thus, in both these patients, despite the relatively short duration of symptoms the features of the disease could be readily discerned. It is well known of course that apparently healthy members of a diseased family may show typical signs of the disease.

Case 12. Man, aged 24 years. Duration of symptoms one year. Increasing myotonia had made it difficult for him to load and fire a rifle. Relaxation of grip was becoming troublesome to execute. There was complaint of slight weakness of the arms but his legs were normal. Myotonia of the hands and wasting of both sternomastoid muscles were the only abnormalities but they were considerable. They sufficed to make the diagnosis.

Case 13. Man, aged 40 years. Duration of symptoms was six months. The only complaints were of weakness and easy fatigue of arms and legs. The weakness was especially troublesome about the neck and shoulders. Yet he showed the characteristic dull and lifeless expression with the heavy eyelids and the 
flabby lips (Fig. 2). The cervical muscles were wasted and weak. Typical myotonic phenomena were demonstrated in his hands and forearms.

Case 16. Woman, aged 29 years. Weakness had begun three years ago but wasting had not previously been detected. She had been incorrectly diagnosed as an example of ankylosing spondylitis but the classical features of myotonia atrophica were readily recognizable.

These cardiac changes were not observed in unaffected members of a family. Ten healthy relatives (nine in the same generation as the diseased members) of some of the above patients were examined. In all ten the electrocardiographic tracings were normal. In one family, only the one unaffected member had a normal electrocardiogram. Unfortunately, in this series there are few young healthy relatives, long-term observation of whom would be helpful in determining the time of onset of the cardiac changes.
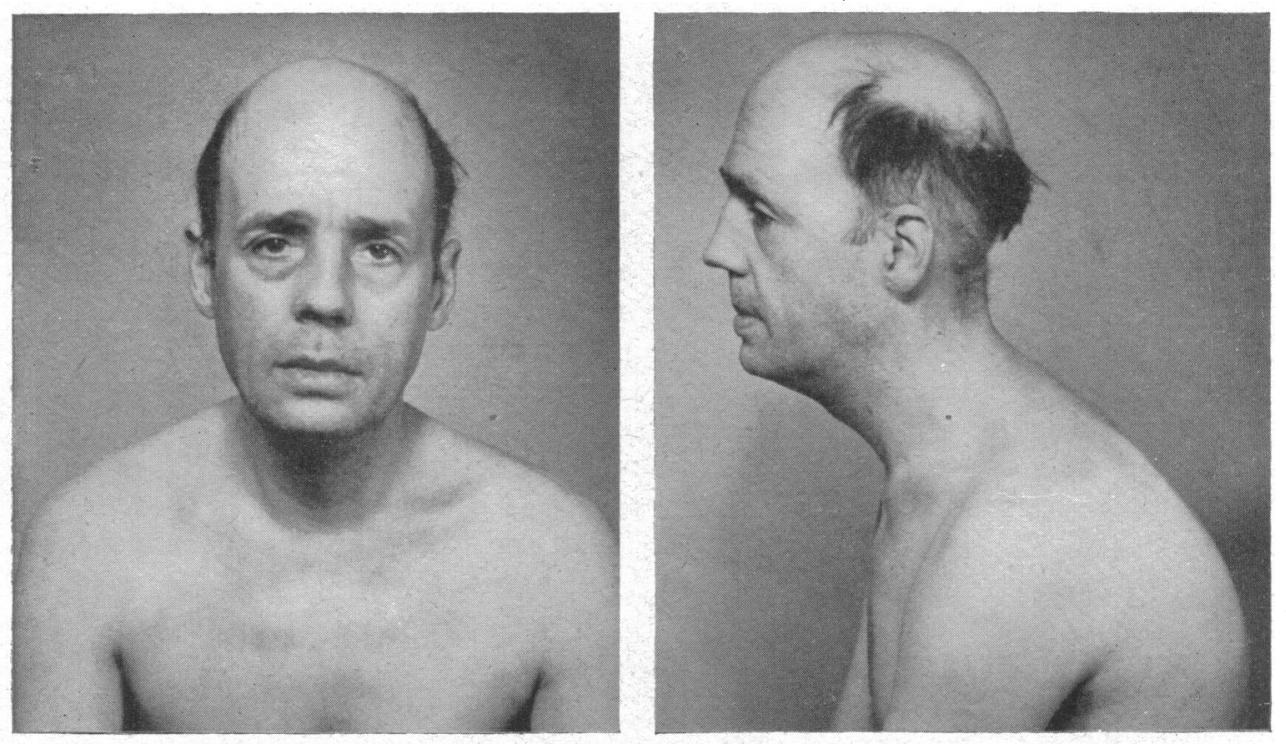

Fig. 2.-Case 13. Duration of symptoms six months; shortest in this series. Yet the signs of the disease can be recognized by the facial appearance and thin neck muscles. The heart was normal.

No doubt the rate and mode of progress of this polysymptomatic disease vary considerably. One finds on the one hand relatively symptomless patients with some of the hallmarks of the disease (premature baldness, wasting of the neck muscles, myasthenic expression) and on the other hand patients in whom mental deterioration and myotonia antedate the other features. When there is much muscular wasting there are always some mental changes, but the reverse is not necessarily true.

Each patient in this series was photographed and it is apparent that a typical example of the disease can hardly fail to be identified by the appearance of the face and neck alone. Indeed, quick recognition of the nature of the malady is probably a commoner experience than diagnosis arrived at by formal examination. The dull apathetic expression, the heavy eyelids, the hollow temples, and the loose mouth, with the characteristic wasting of the masseters and the sternomastoid muscles, are the distinctive signs that catch the eye. The profile view of the patient presents no less striking an appearance. It is then that one sees the true extent of the wasting of the neck muscles with the prominent larynx and the curve forward of the neck.

Cardiac abnormalities are not found in myotonia congenita. In other more common types of muscular dystrophy the majority of observers have found no frequent or characteristic clinical changes in the heart. In myasthenia gravis also the heart is usually normal. 


\section{SUMmarY AND CONCLUSIONS}

Examination of the heart in $\mathbf{1 6}$ cases of myotonia atrophica confirms previous reports that it is frequently involved in the disease.

A small pulse, a relatively low blood pressure, and splitting of the first heart sound in the mitral area are frequent clinical findings. The electrocardiogram may reveal low $\mathbf{P}$ waves and prolongation of the P-R interval.

The heart is usually normal in size.

In my experience, however, these cardiac changes may not be present when the neurological features of the disease are already established. In the two patients with the shortest duration of symptoms the heart was normal. In three further patients with relatively short duration of symptoms the cardiac abnormalities were not remarkable. In the remaining patients the disease was of long standing and some or all of the above-mentioned cardiac changes were commonly found.

The neurological features of this disease develop earlier and are more readily identified than the cardiological signs.

\section{REFERENCES}

Adie, W. S., and Greenfield, J. G. (1923). Brain, 46, 73.

Ask-Upmark, E. (1944). Acta. med. Scand., 116, 502.

Biörck, G., and Nylin, G. (1944). Nordisk, Med., 22, 946.

Black, W. C., and Ravin, A. (1947). Arch. Path., 44, 176.

Broustet, P., and Berguignan, M., and L'Egrer, H. (1945). Arch. Mal. Coeur., 38, 212.

Carrillo, E. G., (1941). Rev. Argent. Cardiol., 8, 122.

Carrot, E., and David, M. (1943). Rev. Neurol., 75, 146.

d'Antona, L. (1935). Minerva Med., 1, 833.

Evans, W. (1944). Brit. Heart J., 6, 41.

Griffith, T. W. (1911-12). Quart. J. Med., 5, 229.

Guillain, G., and Rouques, L. (1932). Ibid., 31, 158.

Havier, P., and Decourt, J. (1933). Rev. Neurol., 2, 468.

Kolb, L. C., and Harvey, A. M., and Whitehill, M. R. (1938). Bull., Johns Hopkins Hosp., $62,188$.

Maas, O., and Zondek, H. (1920). Z. Neur. Psych., 59, 322.

Mondon, H., and Pasquet, D. (1939). Arch. Mal. Coeur, 32, 401.

Röhrer, K. (1916). Dtsch. Nervenheilk, 55, 242.

Segura, R. G., and Lanari, A. (1941). Rev. Argent. Cardiol., 7, 363.

Thaysen, E. H. (1943).' Ugeskr. Laeger., 105, 329.

Thomasen, E. (1948). Myotonia. Trans., by F. B. Carlsen, Aarhuus Stiftsbogtrykkerie A/S.

Waring, J. J., and Ravim, A., and Walker, C. E. Jr. (1940). Arch. intern. Med., 65, 763. 